\title{
Chlorambucil/Rituximab Regimen
}

National Cancer Institute

\section{Source}

National Cancer Institute. Chlorambucil/Rituximab Regimen. NCI Thesaurus. Code C154218.

A chemoimmunotherapy consisting of chlorambucil and rituximab that can be used in the treatment of some forms of non-Hodgkin lymphoma (NHL) and chronic lymphocytic leukemia (CLL). 